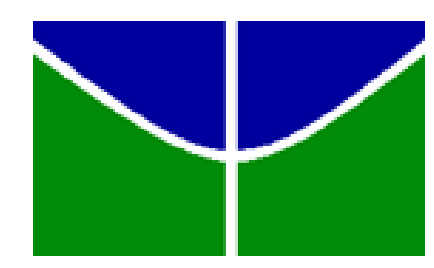

UNIVERSIDADE DE BRASÍLIA

FACULDADE DE CIÊNCIAS DA SAÚDE

DEPARTAMENTO DE ENFERMAGEM

ÍRIS CAROLINE DOS SANTOS

SEGURANÇA DO PACIENTE NA COMPREENSÃO DE ESTUDANTES UNIVERSITÁRIOS DE ENFERMAGEM

BRASÍLIA - DF 
ÍRIS CAROLINE DOS SANTOS

\section{SEGURANÇA DO PACIENTE NA COMPREENSÃO DE ESTUDANTES UNIVERSITÁRIOS DE ENFERMAGEM}

Trabalho de Conclusão de Curso apresentado como requisito parcial para obtenção do Título de Bacharel em Enfermagem pela Faculdade de Ciências da Saúde da Universidade de Brasília.

Área de Concentração: Processo de Cuidar

Linha de Pesquisa: Segurança do Paciente

Orientadora: Profa. Dra. Maria Cristina Soares Rodrigues

BRASÍLIA - DF 


\section{ÍRIS CAROLINE DOS SANTOS}

\section{SEGURANÇA DO PACIENTE NA COMPREENSÃO DE ESTUDANTES UNIVERSITÁRIOS DE ENFERMAGEM}

Trabalho de Conclusão de Curso apresentado como requisito parcial para obtenção do Título de Bacharel em Enfermagem pela Faculdade de Ciências da Saúde da Universidade de Brasília.

Aprovado em:

BANCA EXAMINADORA

Profa. Dra. Maria Cristina Soares Rodrigues

Universidade de Brasília - UnB

Presidente da Banca

Profa. Dra. Claudia Maffini Griboski

Universidade de Brasília - UnB

Membro Efetivo

Profa. Dra. Priscila da Silva Antonio

Universidade de Brasília - UnB

Membro Efetivo

Enfa. Ms Viviane Franzoi da Silva

Secretaria de Estado de Saúde do Distrito Federal - SES-DF

Membro Suplente 


\section{AGRADECIMENTOS}

Sou grata a Deus por me conceder saúde e forças para enfrentar as dificuldades e caminhar rumo aos meus sonhos.

Aos meus pais que são meu porto seguro e não medem esforços para incentivar a conquistar os meus objetivos. Exemplos de determinação, sempre presentes e amorosos me ajudam a ser melhor a cada dia.

À minha irmã Fabíola e sobrinha Isabella, pelo carinho, apoio e conselhos em todos os momentos.

À minha orientadora, Professora Maria Cristina Soares Rodrigues, exemplo admirável de profissional, pela oportunidade e confiança em compartilhar seus conhecimentos, ao suporte e orientação fornecidos para a construção desse trabalho.

À Universidade de Brasília por possibilitar minha formação profissional.

Ao Departamento de Enfermagem e professores, que de forma valiosa contribuíram para meu crescimento acadêmico, além do apoio e contribuição para o desenvolvimento desse estudo.

Aos alunos de graduação em enfermagem pela participação nessa pesquisa e possibilitar sua concretização. 


\section{LISTA DE TABELAS}

Tabela 1. Distribuição das respostas dos estudantes de graduação em enfermagem sobre os aspectos conceituais referentes ao erro humano e a segurança do paciente $(n=242)$

Tabela 2. Distribuição das respostas dos estudantes de graduação em enfermagem sobre os aspectos atitudinais referentes ao erro humano e a segurança do paciente $(n=242)$ 


\section{LISTA DE ABREVIAÇÕES E SIGLAS}

$\begin{array}{ll}\text { CEP/FS-UnB } & \begin{array}{l}\text { Comitê de Ética em Pesquisa da Faculdade de Ciências da Saúde da } \\ \text { Universidade de Brasília }\end{array} \\ \text { CNPq } & \text { Conselho Nacional de Desenvolvimento Científico e Tecnológico } \\ \text { CNS } & \text { Conselho Nacional de Saúde } \\ \text { DCN } & \text { Diretrizes Curriculares Nacionais } \\ \text { DF } & \text { Distrito Federal } \\ \text { MEC } & \text { Ministério da Educação } \\ \text { MS } & \text { Ministério da Saúde } \\ \text { OMS } & \text { Organização Mundial da Saúde } \\ \text { PNSP } & \text { Programa Nacional de Segurança do Paciente } \\ \text { SP } & \text { Segurança do Paciente }\end{array}$


Introduçãão.................................................................................................................................... 8

Métodos............................................................................................................................................. 9

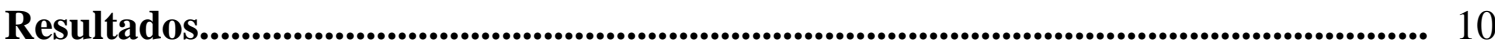

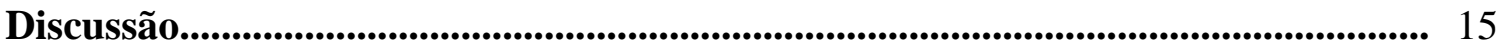

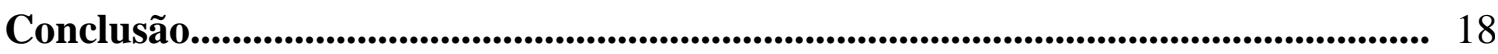

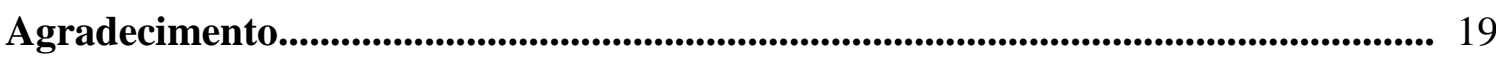

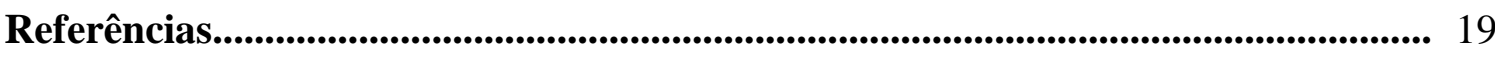

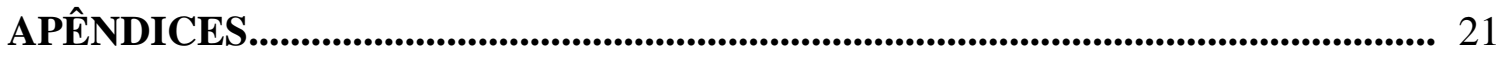

APÊNDICE A - INSTRUMENTO DE PESQUISA................................................... 22

APÊNDICE B - TERMO DE CONSENTIMENTO LIVRE E ESCLARECIDO.. 25

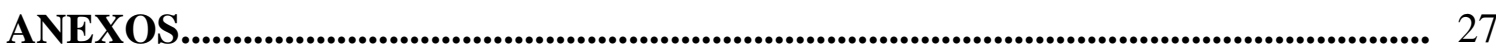

ANEXO A - AUTORIZAÇÃO PARA UTILIZAÇÃO DO INSTRUMENTO

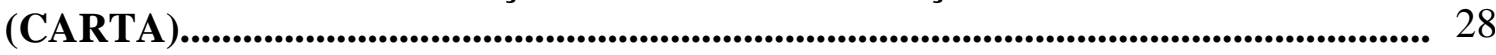

ANEXO B - AUTORIZAÇÃO PARA UTILIZAÇÃO DO INSTRUMENTO (E-

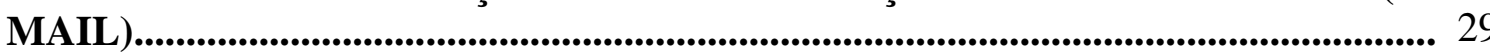

ANEXO C - AUTORIZAÇÃO DA COORDENAÇÃO DO CURSO DE ENFERMAGEM PARA O DESENVOLVIMENTO DA PESQUISA..................... 30 ANEXO D - AUTORIZAÇÃO DA CHEFIA DO DEPARTAMENTO DE ENFERMAGEM PARA O DESENVOLVIMENTO DA PESQUISA..................... 31 ANEXO E - PARECER CONSUBSTANCIADO DO CEP................................... 32 


\section{Segurança do paciente na compreensão de estudantes universitários de enfermagem $^{a}$}

\section{Resumo}

Objetivo: Verificar a compreensão de estudantes de enfermagem de uma instituição pública de ensino superior do Distrito Federal sobre erro humano e segurança do paciente.

Métodos: Estudo transversal e descritivo, realizado nos meses de abril e maio de 2018. Participaram 242 alunos que preencheram um questionário semiestruturado, com variáveis referentes à caracterização sociodemográfica e acadêmica, e aos aspectos conceituais e atitudinais sobre erro humano e segurança do paciente. Os dados obtidos foram tabulados e examinados por análise descritiva.

Resultados: A maioria dos alunos afirma possuir aprendizado formal sobre segurança do paciente, porém, em muitas afirmativas percebe-se a existência de dúvida sobre o que é adequado ou não, principalmente no conflito existente entre a teoria e a prática. Estas fragilidades foram identificadas no ensino fragmentado da temática durante a formação.

Conclusão: Os estudantes possuem boa percepção em identificar falhas nos processos de segurança do paciente. Mudanças no currículo são necessárias, visando adequações para melhorias na abordagem do tema durante a formação, com articulação teórico-prática.

Descritores: Segurança do paciente; Estudantes de enfermagem; Educação em enfermagem; Currículo.

\footnotetext{
${ }^{\text {a }}$ Trabalho de Conclusão de Curso apresentado no formato de artigo científico.
} 


\section{Introdução}

Nas últimas décadas, os cuidados à saúde evoluíram muito, o conhecimento sobre as doenças e os avanços tecnológicos têm contribuído para a melhoria da qualidade e expectativa de vida das pessoas. Assim, um desafio permanente é se manter atualizado para tomada de decisão clínica para oferecer assistência qualificada e com segurança.

Nos diferentes contextos de assistência, as chances de ocorrência do erro humano são enormes, com possibilidades que incidentes aconteçam, expressando-se em implicações diversas aos profissionais, serviços de saúde e à segurança dos pacientes. Segurança do Paciente (SP) é definida como a redução, a um mínimo aceitável, do risco de dano desnecessário associado ao cuidado de saúde, ${ }^{(1)}$ representa uma problemática de abrangente discussão entre os principais envolvidos. ${ }^{(2)}$

A literatura aponta para a fragilidade da SP encontrada nas instituições de saúde decorrente também de lacunas no processo de formação dos profissionais, sobretudo no desenvolvimento teórico-prático, ${ }^{(3)}$ evidenciada pelo obstáculo de incorporar conceitos e conteúdos aprendidos em sala de aula no campo prático, gerando conflitos da teoria com a realidade. $^{(4,5)}$

Muitas vezes, a temática se faz presente nos projetos pedagógicos dos cursos, contudo, de forma desassociada entre as disciplinas e os semestres, dificultando o fornecimento de subsídios necessários para a prática profissional. ${ }^{(2)}$ Cabe destacar a responsabilidade e o papel fundamental que as instituições de ensino têm em propagar a cultura de segurança desde o início da graduação, e assim, ampliar o conhecimento dos estudantes e contribuir de forma efetiva na prática segura e qualificada da assistência. ${ }^{(6)}$

Em decorrência dessa vulnerabilidade, a Organização Mundial de Saúde (OMS) publicou em 2011, um guia para auxiliar na organização do currículo acadêmico nas áreas da saúde, norteando estudantes e educadores no processo de abordagem, ensino e aprendizagem da SP. ${ }^{(7)}$ Em consonância, o Ministério da Saúde (MS) instituiu em 2013 o Programa Nacional de Segurança do Paciente (PNSP), com o objetivo de contribuir para a qualificação do cuidado em saúde, ao utilizar a estratégia de articulação com o Ministério da Educação (MEC), visando a inclusão dessa temática nos currículos dos cursos em saúde de todos os níveis de formação. ${ }^{(8)}$

O MEC possui a importante incumbência de instituir as Diretrizes Curriculares Nacionais (DCN) dos cursos de graduação, inclusive da área da saúde, entretanto, apenas o seu cumprimento não garante que a formação desse profissional seja boa. ${ }^{(4)} \mathrm{Com}$ isso, em 
2017, o Conselho Nacional de Saúde (CNS) se pronunciou a respeito, na resolução $\mathrm{n}^{\circ} 569$, com alguns princípios a serem incorporados nas DCN desses cursos, destacando conformidades com o PNSP que preconiza que a assistência seja embasada no pensamento crítico e as ações dos alunos egressos conduzidas pelas melhores evidências científicas, pautadas em políticas públicas, programas, ações estratégicas e diretrizes vigentes, com foco na preparação e no comprometimento deles em reconhecer e intervir nos riscos, assim como, em reduzir agravos decorrentes do cuidado. ${ }^{(9)}$

Nessa perspectiva, é necessário que novas pesquisas sejam feitas para identificar a atual compreensão dos estudantes acerca do assunto, principalmente no cenário brasileiro, onde há escassez de dados publicados a respeito. ${ }^{(6)}$ Esse conhecimento é fundamental para amparar condutas e estratégias eficazes na formação profissional e consequentemente provocar mudanças positivas na assistência à saúde oferecida à população, colocando a segurança de forma prioritária. ${ }^{(10)}$

A partir de evidências da literatura que apontam à escassez do tema na grade curricular das faculdades da área da saúde e, de outro lado, na perspectiva do abrangente e indispensável conteúdo à prática clínica moderna, emerge a seguinte questão de pesquisa: qual a compreensão de estudantes de graduação em enfermagem acerca do erro humano e segurança do paciente?

Assim, traçou-se como objetivo deste estudo verificar a compreensão de estudantes de enfermagem de uma instituição pública de ensino superior do Distrito Federal sobre erro humano e segurança do paciente.

\section{Métodos}

Trata-se de estudo transversal e descritivo, com abordagem quantitativa, realizado em uma instituição federal de ensino superior do Distrito Federal (DF), Brasil. Estabeleceu-se como população do estudo os estudantes regularmente matriculados no curso de bacharelado em enfermagem, do terceiro ao décimo semestre, tendo em vista o período em que iniciam as atividades práticas estabelecendo contato com o paciente, por meio da disciplina "Vivências Integradoras II" até o último estágio acadêmico com a disciplina "Estágio Supervisionado II". Foram excluídos os estudantes do primeiro e segundo semestres por não terem contato com o paciente em campo prático, os alunos em trancamento de matrícula e a aluna autora do estudo. 
No semestre em que a pesquisa foi realizada, o curso de enfermagem possuía 427 alunos ativos, porém, desta população foram excluídos 127 alunos, sendo que 44 pertenciam ao primeiro semestre, 45 ao segundo semestre, 37 estavam em situação de trancamento de matrícula e a aluna autora do estudo, que resultou em uma população de 300 alunos. Para o cálculo amostral foi considerado o percentual estimado de 50\%, erro amostral de 5\% e grau de confiança de 95\%, obtendo-se estimativa de uma amostra mínima de 169 estudantes, onde foram acrescidos $20 \%$ para perdas, que resultou em 202 alunos.

O instrumento de coleta de dados foi um questionário semiestruturado, autoaplicável, composto por duas partes, onde a primeira é composta por questões abertas referentes à caracterização sociodemográfica e acadêmica dos alunos de enfermagem, e a segunda parte compreende 20 questões fechadas, previamente construídas e validadas por outras pesquisadoras, ${ }^{(10)}$ onde são abordados aspectos conceituais e atitudinais sobre erro humano e segurança do paciente, com respostas medidas por meio de escala Likert, que variam entre concordo, concordo fortemente, não tenho opinião, discordo e discordo fortemente.

A coleta de dados aconteceu nos meses de abril e maio de 2018, após autorização para uso pelas autoras do instrumento, da coordenação do curso de enfermagem e da aprovação do projeto pelo Comitê de Ética em Pesquisa da Faculdade de Ciências da Saúde da Universidade de Brasília - CEP/FS-UnB, com CAAE n. 82254118.0.0000.0030 e parecer n. 2.526.786/2018. Foram respeitadas as normas nacionais e internacionais de ética em pesquisa envolvendo seres humanos, que garante aos estudantes o anonimato e a livre participação da pesquisa, podendo desistir do estudo a qualquer momento.

Os respondentes foram abordados pessoalmente na própria universidade, em momentos de disponibilidade antes e após os horários das aulas, e todos os participantes assinaram o Termo de Consentimento Livre e Esclarecido. Os dados obtidos foram tabulados em uma planilha Excel ${ }^{\circledR}$ e posteriormente submetidos à análise descritiva, com os resultados apresentados em frequência absoluta e relativa.

\section{Resultados}

Dentre a população estabelecida no primeiro semestre de 2018, participaram do estudo 242 estudantes, ou seja, acima do estimado, assim distribuídos: 19 (7,8\%) alunos do terceiro semestre, $31(12,8 \%)$ do quarto, $42(17,4 \%)$ do quinto, $33(13,6 \%)$ do sexto, 27 $(11,2 \%)$ do sétimo, $42(17,4 \%)$ do oitavo, $15(6,2 \%)$ do nono e $33(13,6 \%)$ do décimo. 
Quanto à caracterização dos estudantes, houve predominância do sexo feminino (n=206; $85,1 \%$ ), e apresentaram idade entre 18 e 38 anos, com média de 22,7 anos.

Com relação ao perfil acadêmico, 64 (26,4\%) estudantes responderam que recebem bolsa. A maioria $(n=60,93,7 \%)$ declarou receber apenas um tipo de bolsa, e quatro $(6,3 \%)$ alunos afirmaram receber mais de uma, totalizando 70 bolsas entre cinco modalidades. Prevaleceram bolsas de assistência estudantil, conforme 46 (65,7\%) alunos declararam, seguida das de iniciação científica com $15(21,4 \%)$ e as demais nove $(12,9 \%)$ ficaram entre monitoria, projeto de extensão e estágio extracurricular.

A maioria dos respondentes $160(66,1 \%)$ afirmou possuir aprendizado formal sobre segurança do paciente, e quando questionados sobre o meio de aprendizagem utilizado, assinalaram mais de uma forma de obtenção desse conhecimento, dentre as alternativas do questionário de disciplinas obrigatórias, disciplinas optativas, palestras/simpósios/minicursos e outros, que resultaram em 179 respostas, com a possibilidade de especificá-las. Os meios mais relatados, em ordem decrescente, foram, disciplinas obrigatórias do currículo com 119 $(66,5 \%)$ respostas, seguida das disciplinas optativas mencionadas $24(13,4 \%)$ vezes, depois as palestras/simpósios com $20(11,2 \%)$ e, por fim, outros meios referidos, como estágios extracurriculares, projetos de pesquisa e ligas acadêmicas com $16(8,9 \%)$ respostas.

Considerando as 119 respostas sobre as disciplinas obrigatórias, os acadêmicos puderam nomear as matérias que possibilitaram o conhecimento sobre a temática. Obteve-se um quantitativo de 184 citações de 14 matérias obrigatórias diferentes, dentre as 42 que compõem o currículo de enfermagem. A que obteve maior destaque foi "Processos de Trabalho", correspondente ao quinto semestre, com $60(32,1 \%)$ respostas, seguida de "Semiologia e Semiotécnica Aplicada à Enfermagem", do terceiro semestre, com 36 (19,3\%) e "Fundamentos de Enfermagem", do quarto semestre, com 34 (18,2\%) citações.

Os participantes que fizeram referência às disciplinas optativas, relataram seis matérias distintas, dentre elas está a disciplina específica de Segurança do Paciente, onde apenas $16(6,6 \%)$ respondentes a cursaram, sendo que $12(5,0 \%)$ alunos a realizaram no primeiro semestre de 2016, única vez que foi oferecida pelo departamento do curso, no campus onde a pesquisa foi realizada, e quatro $(1,7 \%)$ estudantes a cursaram em outro campus da universidade, onde também é ofertado curso de graduação em enfermagem.

Quanto aos dados obtidos dos aspectos conceituais (Tabela 1), não houve consenso na afirmativa que cometer erros na área da saúde é inevitável, em que $86(35,5 \%)$ concordaram e $87(36,0 \%)$ discordaram. A maioria dos estudantes concordou que existe uma grande diferença entre o que os profissionais sabem o que é certo e o que é visto diariamente na 
assistência à saúde $(\mathrm{n}=134 ; 55,4 \%)$, que uma das formas de prevenir o erro é trabalhar com maior cuidado $(\mathrm{n}=123 ; 50,8 \%)$ e para a análise do erro humano é relevante saber características individuais da pessoa que cometeu o erro $(n=112 ; 46,3 \%)$.

Ademais, concordaram fortemente que, na ocorrência de um erro todos os envolvidos devem discutir a respeito $(\mathrm{n}=218 ; 90,1 \%)$, e discordaram que profissionais competentes $(n=149 ; 61,6 \%)$ e alunos comprometidos $(n=154 ; 63,6 \%)$ não cometem erros que causam danos aos pacientes.

Tabela 1. Distribuição das respostas dos estudantes de graduação em enfermagem sobre os aspectos conceituais referentes ao erro humano e a segurança do paciente $(n=242)$

\begin{tabular}{|c|c|c|c|c|c|c|c|c|c|c|}
\hline \multirow{2}{*}{ Aspectos Conceituais } & \multicolumn{2}{|c|}{$\mathbf{C}$} & \multicolumn{2}{|c|}{$\mathbf{C F}$} & \multicolumn{2}{|c|}{ NO } & \multicolumn{2}{|c|}{ D } & \multicolumn{2}{|c|}{ DF } \\
\hline & $\mathbf{N}$ & $\%$ & $\mathbf{N}$ & $\%$ & $\mathbf{N}$ & $\%$ & $\mathbf{N}$ & $\%$ & $\mathbf{N}$ & $\%$ \\
\hline $\begin{array}{l}\text { Cometer erros na área da saúde é } \\
\text { inevitável. }\end{array}$ & 86 & 35,5 & 21 & 8,7 & 19 & 7,9 & 87 & 36,0 & 29 & 12,0 \\
\hline $\begin{array}{l}\text { Existe uma grande diferença entre o } \\
\text { que os profissionais sabem, o que é } \\
\text { certo e o que é visto no dia a dia da } \\
\text { assistência à saúde. }\end{array}$ & 134 & 55,4 & 83 & 34,3 & 13 & 5,4 & 8 & 3,3 & 4 & 1,7 \\
\hline $\begin{array}{l}\text { Profissionais competentes não } \\
\text { cometem erros que causam danos aos } \\
\text { pacientes. }\end{array}$ & 36 & 14,9 & 9 & 3,7 & 17 & 7,0 & 149 & 61,6 & 31 & 12,8 \\
\hline $\begin{array}{l}\text { Alunos comprometidos não cometem } \\
\text { erros que causam danos aos pacientes. }\end{array}$ & 24 & 9,9 & 6 & 2,5 & 20 & 8,3 & 154 & 63,6 & 38 & 15,7 \\
\hline $\begin{array}{l}\text { Na vigência de um erro, todos os } \\
\text { envolvidos (profissionais, alunos, } \\
\text { gestores, paciente e família) devem } \\
\text { discutir sua ocorrência. }\end{array}$ & 104 & 43,0 & 114 & 47,1 & 12 & 5,0 & 10 & 4,1 & 2 & 0,8 \\
\hline $\begin{array}{l}\text { Para a análise do erro humano, é } \\
\text { importante saber quais as } \\
\text { características } \quad \text { individuais } \\
\text { profissional que cometeu o erro. }\end{array}$ & 112 & 46,3 & 41 & 16,9 & 59 & 24,4 & 27 & 11,2 & 3 & 1,2 \\
\hline $\begin{array}{l}\text { Depois que um erro ocorre, uma efetiva } \\
\text { estratégia de prevenção é trabalhar com } \\
\text { maior cuidado. }\end{array}$ & 123 & 50,8 & 82 & 33,9 & 21 & 8,7 & 15 & 6,2 & 1 & 0,4 \\
\hline
\end{tabular}

Legenda: C - Concordo; CF - Concordo Fortemente; NO - Não tenho Opinião; D - Discordo; DF - Discordo Fortemente.

Com relação aos aspectos atitudinais (Tabela 2), o maior percentual concordou que para implementar medidas preventivas deve-se analisar sistematicamente os erros $(n=126$; $52,1 \%)$ e que essas duas atitudes são necessárias sempre que alguém for lesado ( $n=125$; $51,7 \%)$. O mesmo ocorreu com relação à comunicação ao professor sobre as condições do 
campo de estágio $(n=108 ; 44,6 \%)$, a comunicação sobre a ocorrência do erro aos responsáveis pelo local de estágio $(n=115 ; 47,5 \%)$ e com os colegas $(n=128 ; 52,9 \%)$. Concordaram também que profissionais não devem tolerar trabalhar em locais que não ofereçam condições adequadas $(n=119 ; 49,2 \%)$ e que os professores realizam medidas corretivas para que os alunos não cometam novos erros $(n=92 ; 38,0 \%)$.

Não houve consenso entre os estudantes sobre a necessidade de relatar a ocorrência do erro sem danos ao paciente e família, situação na qual $64(26,4 \%)$ concordaram e $80(33,1 \%)$ discordaram, assim como, $76(31,4 \%)$ concordaram sobre comunicar a família e o paciente sobre o acontecimento de erros e a maioria $86(35,5 \%)$ não opinou.

Discordaram fortemente que apenas os médicos podem determinar a causa dos erros $(\mathrm{n}=179 ; 74,0 \%)$, e $208(85,9 \%)$ discordaram ou discordaram fortemente que os sistemas para registro dos erros fazem pouca diferença para redução de novas ocorrências.

Quanto à afirmativa de realizar estágio em locais que promovem boas práticas para a segurança do paciente, $98(40,5 \%)$ discordaram, $56(23,1 \%)$ não opinaram e $54(22,3 \%)$ concordaram. Quando identificadas situações que necessitam de melhorias, 83 (34,3\%) discordaram e $85(35,1 \%)$ não tiveram opinião sobre receber apoio da instituição para promover práticas seguras. 
Tabela 2. Distribuição das respostas dos estudantes de graduação em enfermagem sobre os aspectos atitudinais referentes ao erro humano e a segurança do paciente $(n=242)$

\begin{tabular}{|c|c|c|c|c|c|c|c|c|c|c|}
\hline \multirow{2}{*}{ Aspectos Atitudinais } & \multicolumn{2}{|c|}{ C } & \multicolumn{2}{|c|}{$\mathbf{C F}$} & \multicolumn{2}{|c|}{ NO } & \multicolumn{2}{|c|}{ D } & \multicolumn{2}{|c|}{ DF } \\
\hline & $\mathbf{N}$ & $\%$ & $\mathbf{N}$ & $\%$ & $\mathbf{N}$ & $\%$ & $\mathbf{N}$ & $\%$ & $\mathbf{N}$ & $\%$ \\
\hline $\begin{array}{l}\text { Profissionais não devem tolerar } \\
\text { trabalhar em locais que não oferecem } \\
\text { condições adequadas para o cuidado } \\
\text { prestado ao paciente. }\end{array}$ & 119 & 49,2 & 40 & 16,5 & 25 & 10,3 & 50 & 20,7 & 8 & 3,3 \\
\hline $\begin{array}{l}\text { Para implementar medidas de } \\
\text { prevenção de erros humanos, sempre se } \\
\text { deve instituir uma análise sistemica dos } \\
\text { fatos. }\end{array}$ & 126 & 52,1 & 99 & 40,9 & 15 & 6,2 & 2 & 0,8 & 0 & 0,0 \\
\hline $\begin{array}{l}\text { É necessário implementar análise } \\
\text { sistêmica de erros na área da saúde, } \\
\text { mas medidas preventivas precisam ser } \\
\text { adotadas sempre que alguém for } \\
\text { lesado. }\end{array}$ & 125 & 51,7 & 78 & 32,2 & 14 & 5,8 & 22 & 9,1 & 3 & 1,2 \\
\hline $\begin{array}{l}\text { Sempre comunico a meu professor } \\
\text { sobre a presença de condições no } \\
\text { campo de estágio que favorecem a } \\
\text { ocorrência do erro. }\end{array}$ & 108 & 44,6 & 68 & 28,1 & 37 & 15,3 & 21 & 8,7 & 8 & 3,3 \\
\hline $\begin{array}{l}\text { Sempre comunico } \\
\text { professor/gestor/responsável pelo local } \\
\text { de estágio sobre a ocorrência de um } \\
\text { erro. }\end{array}$ & 115 & 47,5 & 74 & 30,6 & 26 & 10,7 & 26 & 10,7 & 1 & 0,4 \\
\hline $\begin{array}{l}\text { Sempre comunico ao meu colega sobre } \\
\text { a ocorrência do erro. }\end{array}$ & 128 & 52,9 & 65 & 26,9 & 32 & 13,2 & 16 & 6,6 & 1 & 0,4 \\
\hline $\begin{array}{l}\text { Sempre comunico ao paciente e sua } \\
\text { família sobre a ocorrência do erro. }\end{array}$ & 76 & 31,4 & 27 & 11,2 & 86 & 35,5 & 46 & 19,0 & 7 & 2,9 \\
\hline $\begin{array}{l}\text { Se não ocorre dano ao paciente, deve- } \\
\text { se analisar se há necessidade de relatar } \\
\text { a ocorrência do erro ao paciente e } \\
\text { família. }\end{array}$ & 64 & 26,4 & 25 & 10,3 & 48 & 19,8 & 80 & 33,1 & 25 & 10,3 \\
\hline $\begin{array}{l}\text { Os professores sempre realizam } \\
\text { medidas corretivas com o aluno para } \\
\text { que ele não cometa novos erros. }\end{array}$ & 92 & 38,0 & 43 & 17,8 & 41 & 16,9 & 59 & 24,4 & 7 & 2,9 \\
\hline $\begin{array}{l}\text { Sistemas para relatar a ocorrência dos } \\
\text { erros fazem pouca diferença na redução } \\
\text { de futuros erros. }\end{array}$ & 15 & 6,2 & 6 & 2,5 & 13 & 5,4 & 94 & 38,8 & 114 & 47,1 \\
\hline $\begin{array}{l}\text { Apenas os médicos podem determinar } \\
\text { a causa da ocorrência do erro. }\end{array}$ & 1 & 0,4 & 1 & 0,4 & 10 & 4,1 & 51 & 21,1 & 179 & 74,0 \\
\hline $\begin{array}{l}\text { Sempre realizo atividades de estágio } \\
\text { em locais que promovem boas práticas } \\
\text { para a promoção da segurança do } \\
\text { paciente. }\end{array}$ & 54 & 22,3 & 17 & 7,0 & 56 & 23,1 & 98 & 40,5 & 17 & 7,0 \\
\hline
\end{tabular}


Sempre que identifico situações que necessitam melhorias, recebo apoio da $\begin{array}{lllllllllllll}\text { instituição para implementação de } & 31 & 12,8 & 10 & 4,1 & 85 & 35,1 & 83 & 34,3 & 33 & 13,6\end{array}$ medidas que promovam práticas seguras.

Legenda: C - Concordo; CF - Concordo Fortemente; NO - Não tenho Opinião; D - Discordo; DF - Discordo Fortemente

\section{Discussão}

A pesquisa tem como limitação o propósito único de traçar diagnóstico situacional sobre a compreensão da temática na perspectiva dos estudantes de enfermagem, embora há que se destacar a importância de se reconhecer respostas que possam contribuir com o reconhecimento do assunto em tela para a obtenção do panorama sobre a educação da SP no contexto do ensino superior. Desta forma, esse estudo fornece dados que podem embasar a discussão para se apontar a estratégias e à implementação de necessárias adequações curriculares. Como possibilidade de um estudo mais amplo da problemática, um estudo analítico e com abordagem mista (qualitativa e quantitativa), envolvendo a triangulação de dados por meio da análise curricular das disciplinas, do currículo oculto e o acompanhamento dos alunos em campo prático, contribuiria para uma compreensão mais abrangente do tema investigado.

Os resultados mostram predominância de estudantes do sexo feminino e idade similares a outras pesquisas brasileiras realizadas nesse mesmo seguimento. ${ }^{(5,6)}$ Com relação às bolsas recebidas pelos alunos, assemelha-se a outra pesquisa, também realizada em instituição federal de ensino superior, e dentre os alunos que as recebem, o maior número estão as bolsas assistenciais seguida de iniciação científica. ${ }^{(6)}$

A maioria dos respondentes afirmou ter aprendizado formal sobre segurança do paciente. Ainda que o tema seja transversal, menos da metade das matérias do currículo foram citadas como meio de conhecimento, e as que mais foram relatadas, são pertencentes à primeira metade do curso de graduação. Esse dado evidencia a fragmentação do conteúdo e a falta de continuidade da abordagem do tema em sala de aula e campo prático ao longo da formação, além de que, nessas disciplinas apenas alguns tópicos sobre SP vinculados ao seu tema central são tratados.

Estudo realizado com profissionais da área da saúde ressalta a crítica existente na formação desses profissionais, que acreditam que os docentes deveriam abordar esse tema em todas as disciplinas, de forma menos pontual e mais crítica e reflexiva buscando conhecimentos específicos da sua área de atuação. ${ }^{(11)}$ 
A não disponibilização da disciplina específica de SP configura outra fragilidade na formação profissional, pois, a maioria dos alunos não a cursou, por não constar como disciplina obrigatória no currículo do curso. Considerando que a inserção de uma matéria exclusiva sobre essa temática no currículo proporcionaria maior embasamento aos estudantes nas outras disciplinas, seria também mais uma forma de reduzir as lacunas encontradas no processo de formação, além de atender as recomendações da OMS e do PNSP.

A necessidade de readequação curricular de cursos na área da saúde para a promoção da cultura de segurança em futuros profissionais também foram mencionadas em outras pesquisas, que acreditam ser indispensável a exploração do tema transversalmente e com maior profundidade no processo de ensino-aprendizagem, assim como, a melhoria da integração com a realidade assistencial, para atender às principais demandas da sociedade, especialmente no que se refere a aspectos socioculturais. ${ }^{(5,11)}$

Grande parte dos acadêmicos concordou que no exercício prático da profissão existem divergências entre saber e fazer o que é correto. Estudos realizados para entender a ocorrência dessa lacuna teórico-prática, sinalizaram que as universidades oferecem a temática SP de forma teórica e abstrata, evidenciada pela dificuldade de sua aplicação pelos alunos, que consequentemente reflete na prática profissional. ${ }^{(12)}$ Essa maneira de preferir conhecer a prática, diversamente de aprender em prática, implica em cobranças diferentes de conhecimento, onde a universidade exige teoria e o local de trabalho competências práticas. ${ }^{(3)}$

A causa do conflito teórico-prático da SP no entendimento dos estudantes desse estudo, pode estar implícito na qualificação dos professores para ensinar e problematizar a temática, assim como, na metodologia adotada e no vínculo existente entre os docentes da prática e os enfermeiros preceptores, onde ambos devem estar capacitados, em sintonia e colaborativos em fortalecer vínculos entre a universidade e o local de estágio. ${ }^{(11,13)}$

Quanto à metodologia, estudo realizado na Coreia do Sul, obteve resultados positivos na melhora de habilidades dos alunos ao aplicar um treinamento sobre percepção de riscos, de modo ativo, promovendo reflexão e discussão de medidas preventivas para as diversas situações apresentadas. ${ }^{(12)}$

Não houve consenso entre os estudantes sobre o acometimento de erros na saúde ser inevitável. Alguns acreditam no erro como algo natural do ser humano, passível de falhas, e outros veem as barreiras para a promoção da cultura de segurança como métodos eficazes na sua prevenção. Com relação à causa dos erros, a maioria dos respondentes discordaram fortemente que apenas os médicos possam a determinar, entendendo que os demais profissionais também são protagonistas para a promoção da SP. 
Os estudantes discordaram que profissionais competentes e alunos comprometidos não cometem erros que causam danos aos pacientes, que infere a ideia de que qualquer pessoa está sujeita ao erro, independente de ser formada ou não. Isso contribui com a análise sistêmica do erro, na qual os alunos concordaram ser necessária para adotar medidas preventivas e sempre que alguém for lesado. Desta forma, a pessoa que cometeu o erro diretamente não é punida nem culpabilizada por isso, pois acredita-se que ela também é vítima de um processo de cultura de segurança fragilizado, no que é constituído de muitos fatores, não só de valores, crenças, conhecimentos e competências individuais, mas coletivas e institucionais também.

No entanto, é notório o sentimento de culpabilização individual pela ocorrência do erro em estudantes, quando afirmam que, para a análise do erro é relevante saber as características individuais de quem o cometeu e não em fatores sistêmicos contribuintes, o mesmo ocorre em concordarem que uma das formas de evitá-lo é trabalhar com maior cuidado. Pesquisas demonstram que o sentimento de culpa do indivíduo não é eficiente na prevenção de novos erros ${ }^{(13,14)}$, e instituições que promovem esse comportamento passam a falsa ideia de segurança, quando o ideal seria entender como e por que os erros acontecem, eliminar fatores contribuintes e criar barreiras eficazes. ${ }^{(14)}$

A maioria dos estudantes não opinou sobre comunicar o paciente e a família sobre a ocorrência de erros. Pesquisadores acreditam que isso decorre do processo de formação que não prepara o futuro profissional para lidar com essas situações, que ainda são relacionadas a sentimentos ruins, como culpa, vergonha, incapacidade e falta de conhecimento. ${ }^{(11)}$

Apesar de os estudantes compreenderem que ao ocorrer um erro todos os envolvidos devem discutir a respeito, corroborando com a afirmativa anterior, não houve consenso dos respondentes sobre a necessidade de relatar o erro sem danos ao paciente e familiares. Isso confirma que é difícil promover discussões construtivas sobre os erros, sobretudo com os pacientes, e que a cultura de punição ainda é enraizada nas instituições, em que o relato acontece quando o erro gera dano ao paciente e se torna identificável não só para quem o atingiu diretamente. ${ }^{(14)}$

Porém, quando foi abordada a comunicação ao professor sobre as condições do campo de estágio e sobre a ocorrência do erro aos responsáveis pelo campo prático e aos colegas, os estudantes, em sua maioria, confirmaram as afirmativas. Isso demonstra uma boa relação de confiança entre aluno e professor/preceptor. Também relataram boa conduta dos professores, ao afirmarem que eles realizam medidas corretivas para evitar recorrência de erros por estudantes. 
É importante ressaltar que o paciente deve ser visto como agente de seu cuidado, lhe cabendo o direito de participar das decisões e ser informado sobre as condutas, riscos e erros que lhe acomete. Estabelecer comunicação clara, direta e transparente com ele e seus familiares é peça fundamental para promover a cultura de segurança, criar vínculo e confiança para um cuidado mais seguro. ${ }^{(14)}$ Os professores e preceptores devem ensinar a forma adequada de se comunicar com quem recebe o cuidado, e além de instruir sobre a forma de registro dos erros, precisam ser exemplos dessas atitudes positivas. ${ }^{(13)}$

Sobre a notificação dos erros, predominou a discordância de que os sistemas para registro dos erros fazem pouca diferença para redução de recorrências. Isso porque, apesar dos sistemas de notificação serem cruciais para o monitoramento situacional, o reconhecimento do erro e o planejamento de estratégias preventivas, em decorrência da cultura de culpa ainda existente, o medo de ser reconhecido ou exposto e até mesmo a falta de conhecimento sobre a importância e de como realizar a notificação, torna esse recurso limitado pelas subnotificações. ${ }^{(6)}$ Neste sentido, necessário se faz estimular desde o início da graduação o registro dos erros e propagar uma cultura livre de culpa, e que os utilizem como meio de aprendizagem e não punição.

Os estudantes afirmaram que os profissionais não devem tolerar trabalhar em locais que não ofereçam boas condições para a prestação do cuidado, porém, sobre os campos em que são realizados os estágios, a maioria discordou que o ambiente promove boas práticas, que em parte é positivo, pois indica que os acadêmicos conseguem identificar as fragilidades existentes, mas, por outro lado, traz preocupação sobre as condições de aprendizagem prática, porque quando os alunos identificam situações que necessitam de melhorias, a maior parte não opinou e quase o mesmo número discordou sobre receber apoio da instituição para promover práticas seguras, o que dificulta na propagação da cultura de segurança.

Estes fatores mencionados são fundamentais para prestar assistência segura, e a carência desses recursos podem ser desencadeadores de desestímulo entre os alunos, ao se depararem com a realidade e não receberem o apoio para modificá-la, traduzidos em sentimento de impotência e conflito entre o que é certo e o que é vivenciado.

\section{Conclusão}

Os estudantes possuem boa percepção em identificar falhas nos processos de segurança do paciente. Mudanças no currículo são necessárias, visando adequações para melhorias na abordagem do tema durante a formação, com articulação teórico-prática. 


\section{Agradecimento}

Pesquisa realizada com o apoio do Conselho Nacional de Desenvolvimento Científico e Tecnológico - CNPq, processo n. 129137/2017-0.

\section{Referências}

1. Brasil. Ministério da Saúde. Fundação Oswaldo Cruz; Agência Nacional de Vigilância Sanitária. Documento de referência para o Programa Nacional de Segurança do Paciente. Brasília: Ministério da Saúde, 2014. 40 p.

2. Melleiro MM. Thematic patient safety in the curricular matrices of undergraduate schools in nursing and obstetrics. Rev baiana enferm [Internet]. 2017 [cited 2018 Mar 20]; 31(2):e16814. Available from: http://dx.doi.org/10.18471/rbe.v31i2.16814.

3. Murray M, Sundin D, Cope V. New graduate registered nurses' knowledge of patient safety and practice: A literature review. J Clin Nurs [Internet]. 2018 [cited 2018 Mar 22]; 27:31-47. Available from: https://doi.org/10.1111/jocn.13785.

4. Trevisan D, Testi C, Carmona E, Silva E. Education and professional nursing practice: interfaces for reflection. Rev. baiana de saúde pública [Internet]. 2014 [cited 2018 Mar 22]; 38(1):155-62. Available from: doi:10.22278/2318-2660.2014.v38.n1.a737.

5. Bim LL, Bim FL, Silva AMB, Sousa AFL, Hermann PRS, Andrade D, Hass VJ. Theoretical-practical acquisition of topics relevant to patient safety: dilemmas in the training of nurses. Esc. Anna Nery [Internet]. 2017 [cited 2018 Apr 05]; 21(4):e20170127. Available from: http://dx.doi.org/10.1590/2177-9465-ean-2017-0127.

6. Cauduro GMR, Magnago TSBS, Andolhe R, Lanes TC, Dal Ongaro J. Patient safety in the understanding of health care students. Rev Gaúcha Enferm [Internet]. 2017 [cited 2018 Apr 05]; 38(2):e64818. Available from: http://dx.doi.org/10.1590/1983-1447.2017.02.64818.

7. World Health Organization. Patient safety curriculum guide: multi-professional edition. Geneva; 2011 [cited 2018 Apr 03]. Available from: http://apps.who.int/iris/bitstream/10665/44641/1/9789241501958_eng.pdf 6 .

8. Brasil. Ministério da Saúde. Portaria n. 529 de 01 de abril de 2013. Institui o Programa Nacional de Segurança do Paciente (PNSP). Diário Oficial da União, Brasília (DF), 2 de abr 2013. http://bvsms.saude.gov.br/bvs/saudelegis/gm/2013/prt0529_01_04_2013.html.

9. Brasil. Ministério da Saúde. Conselho Nacional de Saúde. Resolução no 569 de 8 de dezembro de 2017. Brasília, DF. 
10. Yoshikawa JM, Sousa BEC, Peterlini MAS, Kusahara DM, Pedreira MLG, Avelar AFM. Comprehension of undergraduate students in nursing and medicine on patient safety. Acta Paul Enferm [Internet]. 2013 [cited 2018 Mar 03]; 26(1):21-9. Available from: http://dx.doi.org/10.1590/S0103-21002013000100005.

11. Wegner W, Silva SC, Kantorski KJ, Predebon CM, Sanches MO, et al. Education for culture of patient safety: Implications to professional training. Esc Anna Nery Rev Enferm [Internet]. 2016 [cited 2018 Jun 02]; 20(3):e20160068. Available from: http://dx.doi.org/10.5935/1414-8145.20160068.

12. Kim CH, Jeong SY, Kwon MS. Effects of hazard perception training (HPT) on nursing students' risk sensitivity to patient safety and developing safety control confidence. Appl Nurs Res [Internet]. 2018 [cited 2018 Jun 02]39 160-166. Available from: https://doi.org/10.1016/j.apnr.2017.10.020.

13. Jang H, Lee N-J. Patient safety competency and educational needs of nursingeducators in South Korea. PLoS ONE [Internet]. 2017 [cited 2018 Jun 02] 12(9):e0183536. Available from: https://doi.org/10.1371/journal.pone.0183536.

14. Eberle CC, Silva APSS. Nursing students' understanding on patient safety. Rev baiana enferm [Internet]. 2016; [cited 2018 Jun 02]30(4):1-9. Available from: http://dx.doi.org/10.18471/rbe.v30i4.21701. 
APÊNDICES 


\section{APÊNDICE A - INSTRUMENTO DE PESQUISA}

\section{Universidade de}

\section{Universidade de Brasília}

Professora Orientadora: Dra. Maria Cristina Soares Rodrigues

Aluna: Íris Caroline dos Santos - Matrícula: 14/0074881

Título: "O entendimento do erro humano e a segurança do paciente na visão dos estudantes de enfermagem".

Prezado estudante,

Esta pesquisa tem como objetivo verificar o entendimento dos estudantes de enfermagem sobre a segurança do paciente e o erro humano. Sua participação é muito importante, pois contribuirá para a identificação do diagnóstico situacional do conhecimento dos alunos sobre o tema.

Sua participação é totalmente voluntária e se dará por meio do preenchimento de um questionário dividido em duas partes, onde a primeira corresponde a dados sociodemográficos e acadêmicos, e a segunda parte de questões referentes a aspectos conceituais e atitudinais sobre segurança do paciente e o erro humano.

$\mathrm{O}$ preenchimento do instrumento deverá ser feito à caneta, e na segunda parte do questionário, apenas uma resposta para cada item deverá ser marcada, conforme a que melhor adequar em seu julgamento. Sinta-se à vontade para tirar qualquer dúvida tanto em relação à pesquisa quanto na forma do preenchimento dos itens.

\section{PARTE A}

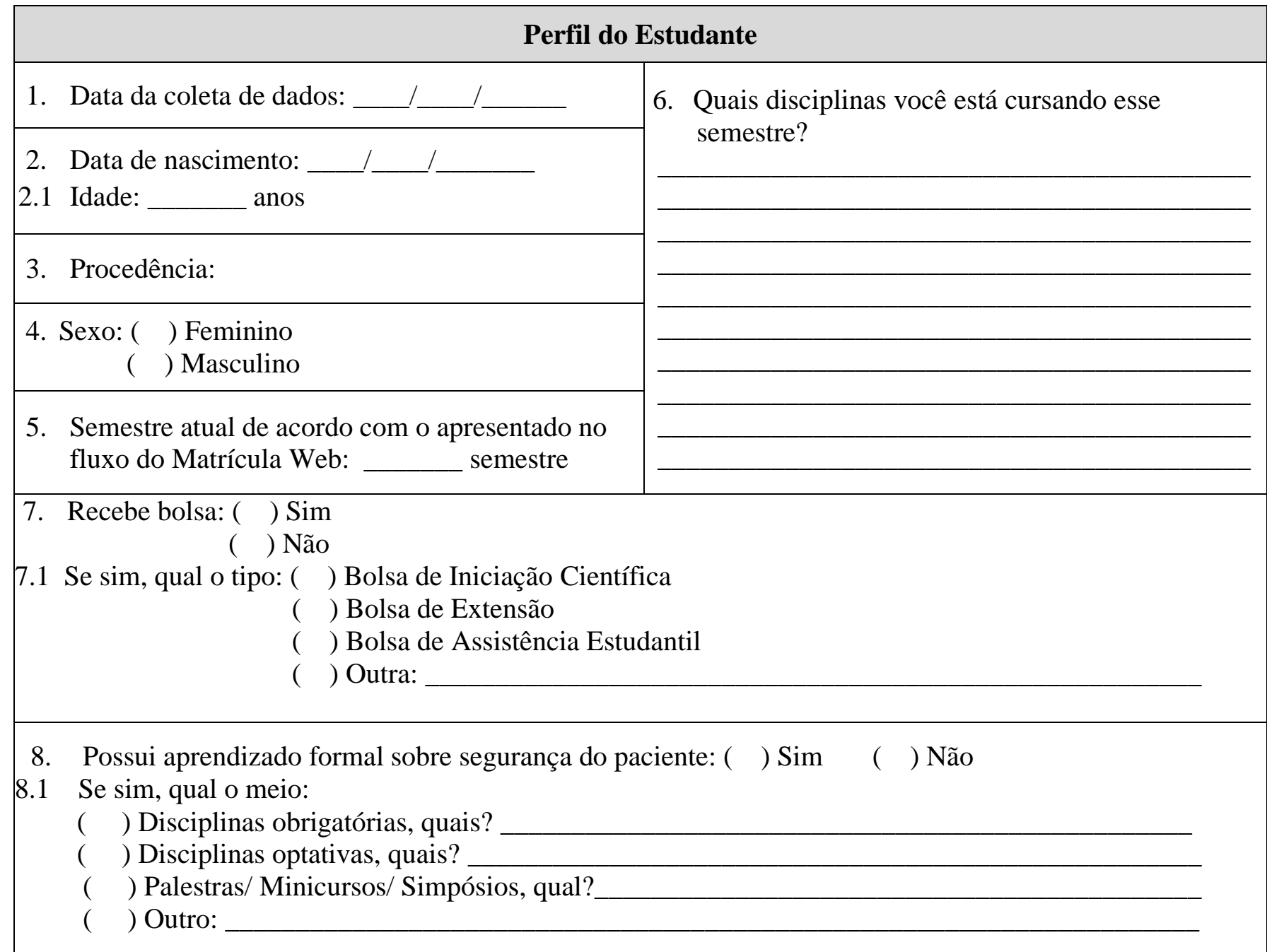


PARTE B - Questionário: Compreensão dos alunos de cursos de graduação em enfermagem sobre segurança do paciente (Yoshikawa et al., 2013).

Tabela 1. Aspectos conceituais referentes ao erro humano e à segurança do paciente, segundo a compreensão de alunos dos cursos de graduação.

\begin{tabular}{|l|l|l|l|l|l|}
\hline \multicolumn{1}{|c|}{ Aspectos Conceituais } & Concordo & $\begin{array}{c}\text { Concordo } \\
\text { Fortemente }\end{array}$ & $\begin{array}{c}\text { Não tenho } \\
\text { Opinião }\end{array}$ & Discordo & $\begin{array}{c}\text { Discordo } \\
\text { Fortemente }\end{array}$ \\
\hline $\begin{array}{l}\text { 1- Cometer erros na área da saúde é } \\
\text { inevitável }\end{array}$ & & & & & \\
\hline $\begin{array}{l}\text { 2- Existe uma grande diferença entre o que } \\
\text { os profissionais sabem, o que é certo e o } \\
\text { que é visto no dia a dia da assistência à } \\
\text { saúde }\end{array}$ & & & & & \\
\hline $\begin{array}{l}\text { 3- Profissionais competentes não cometem } \\
\text { erros que causam danos aos pacientes }\end{array}$ & & & & & \\
\hline $\begin{array}{l}\text { 4- Alunos comprometidos não cometem } \\
\text { erros que causam danos aos pacientes }\end{array}$ & & & & & \\
\hline $\begin{array}{l}\text { 5- Na vigência de um erro, todos os } \\
\text { envolvidos (profissionais, alunos, gestores, } \\
\text { paciente e família) devem discutir sua } \\
\text { ocorrência }\end{array}$ & & & & & \\
\hline $\begin{array}{l}\text { 6- Para a á́lise do erro humano, é } \\
\text { importante saber quais as características } \\
\text { individuais do profissional que cometeu o } \\
\text { erro }\end{array}$ & & & & & \\
\hline $\begin{array}{l}\text { 7- Depois que um erro ocorre, uma efetiva } \\
\text { estratégia de prevenção é trabalhar com } \\
\text { maior cuidado }\end{array}$ & & & & & \\
\hline
\end{tabular}

Tabela 2. Aspectos atitudinais referentes ao erro humano e a segurança do paciente, segundo compreensão de alunos dos cursos de graduação.

\begin{tabular}{|c|c|c|c|c|c|}
\hline Aspectos Atitudinais & Concordo & $\begin{array}{c}\text { Concordo } \\
\text { Fortemente }\end{array}$ & $\begin{array}{c}\text { Não tenho } \\
\text { Opiniãoo }\end{array}$ & Discordo & $\begin{array}{c}\text { Discordo } \\
\text { Fortemente }\end{array}$ \\
\hline $\begin{array}{l}\text { 8- Profissionais não devem tolerar trabalhar } \\
\text { em locais que não oferecem condições } \\
\text { adequadas para o cuidado prestado ao } \\
\text { paciente }\end{array}$ & & & & & \\
\hline $\begin{array}{l}\text { 9- Para implementar medidas de prevenção } \\
\text { de erros humanos, sempre se deve instituir } \\
\text { uma análise sistêmica dos fatos }\end{array}$ & & & & & \\
\hline $\begin{array}{l}\text { 10- É necessário implementar análise } \\
\text { sistêmica de erros na área da saúde, mas } \\
\text { medidas preventivas precisam ser adotadas } \\
\text { sempre que alguém for lesado }\end{array}$ & & & & & \\
\hline $\begin{array}{l}\text { 11- Sempre comunico a meu professor } \\
\text { sobre a presença de condições no campo de } \\
\text { estágio que favorecem a ocorrência do erro }\end{array}$ & & & & & \\
\hline $\begin{array}{l}12-\quad \text { Sempre } \quad \text { comunico } \\
\text { professor/gestor/responsável pelo local de } \\
\text { estágio sobre a ocorrência de um erro }\end{array}$ & & & & & \\
\hline $\begin{array}{l}\text { 13- Sempre comunico ao meu colega sobre } \\
\text { a ocorrência do erro }\end{array}$ & & & & & \\
\hline
\end{tabular}




\begin{tabular}{|l|l|l|l|l|l|}
\hline \multicolumn{1}{|c|}{ Aspectos Atitudinais } & Concordo & $\begin{array}{c}\text { Concordo } \\
\text { Fortemente }\end{array}$ & $\begin{array}{c}\text { Não tenho } \\
\text { Opinião }\end{array}$ & Discordo & $\begin{array}{c}\text { Discordo } \\
\text { Fortemente }\end{array}$ \\
\hline $\begin{array}{l}\text { 14- Sempre comunico ao paciente e sua } \\
\text { família sobre a ocorrência do erro }\end{array}$ & & & & \\
\hline $\begin{array}{l}\text { 15- Se não ocorre dano ao paciente, deve-se } \\
\text { analisar se há necessidade de relatar a } \\
\text { ocorrência do erro ao paciente e família }\end{array}$ & & & & & \\
\hline $\begin{array}{l}\text { 16- Os professores sempre realizam } \\
\text { medidas corretivas com o aluno para que } \\
\text { ele não cometa novos erros }\end{array}$ & & & & & \\
\hline $\begin{array}{l}\text { 17- Sistemas para relatar a ocorrência dos } \\
\text { erros fazem pouca diferença na redução de } \\
\text { futuros erros }\end{array}$ & & & & & \\
\hline $\begin{array}{l}\text { 18- Apenas os médicos podem determinar a } \\
\text { causa da ocorrência do erro }\end{array}$ & & & & & \\
\hline $\begin{array}{l}\text { 19- Sempre realizo atividades de estágio em } \\
\text { locais que promovem boas práticas para a } \\
\text { promoção da segurança do paciente }\end{array}$ & & & & & \\
\hline $\begin{array}{l}\text { 20- Sempre que identifico situações que } \\
\text { necessitam melhorias, recebo apoio da } \\
\text { instituição para implementação de medidas } \\
\text { que promovam práticas seguras }\end{array}$ & & & & & \\
\hline
\end{tabular}

Referência: YOSHIKAWA, J. M. et al. Compreensão de alunos de cursos de graduação em enfermagem e medicina sobre segurança do paciente. Acta Paulista de Enfermagem, v. 26, n. 1, p. 21-29, 2013. 


\section{APÊNDICE B - TERMO DE CONSENTIMENTO LIVRE E ESCLARECIDO}

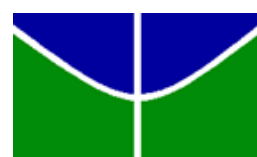

UNIVERSIDADE DE BRASÍLIA

FACULDADE DE CIÊNCIAS DA SAÚDE

DEPARTAMENTO DE ENFERMAGEM

\section{Termo de Consentimento Livre e Esclarecido - TCLE}

Convidamos você a participar voluntariamente do projeto de pesquisa " $O$ entendimento do erro humano e a segurança do paciente na visão dos estudantes de enfermagem", sob a responsabilidade da professora orientadora Maria Cristina Soares Rodrigues e da aluna pesquisadora Íris Caroline dos Santos. O projeto se propõe a investigar a compreensão dos alunos de Enfermagem da Universidade de Brasília, Campus Darcy Ribeiro, sobre aspectos conceituais e atitudinais referentes ao erro humano e a segurança do paciente, e se destina à elaboração do trabalho de pesquisa a ser apresentado na disciplina Trabalho de Conclusão de Curso 2, do Curso de Graduação do Departamento de Enfermagem da Universidade de Brasília.

O objetivo desta pesquisa é verificar o entendimento de estudantes de enfermagem sobre o erro humano e a segurança do paciente na formação, visto que, a obtenção desse conhecimento na área da saúde, como a enfermagem, é fundamental para a formação de um profissional qualificado e consciente de suas responsabilidades na prestação do cuidado ao paciente, sem gerar danos ao mesmo.

Você receberá todos os esclarecimentos necessários antes e no decorrer da pesquisa e lhe asseguramos que seu nome não aparecerá sendo mantido o mais rigoroso sigilo pela omissão total de quaisquer informações que permitam identificá-lo(a).

A sua participação se dará por meio do preenchimento de um questionário, que será entregue após a assinatura do TCLE, em um único encontro, na própria Universidade de Brasília, com tempo total estimado para respondê-lo em 20 minutos, na data e horário combinado previamente. $\mathrm{O}$ questionário será recolhido pela pesquisadora.

Os riscos decorrentes de sua participação na pesquisa abrangem possível desconforto ao responder questões de ordem pessoal e de sua vida acadêmica, cansaço devido ao número de itens do questionário a serem respondidos, além de ansiedade ou tristeza por lembranças de acontecimentos durante as aulas teóricas e/ou práticas, mas que serão minimizados com esclarecimentos necessários antes e no decorrer da pesquisa. Se você aceitar participar, estará contribuindo com a identificação do diagnóstico situacional do conhecimento dos alunos de enfermagem sobre o erro humano e a segurança do paciente, para que se possa indicar a ações de melhorias no currículo vigente, que possibilitem maior esclarecimento dos estudantes e formação de futuros profissionais mais preparados e capacitados para atuarem na perspectiva da segurança do paciente.

Você pode se recusar a responder qualquer questão que lhe traga constrangimento, podendo desistir de participar da pesquisa em qualquer momento sem nenhum prejuízo para você. Sua participação é voluntária, isto é, não há pagamento por sua colaboração.

Todas as despesas que você tiver relacionadas diretamente ao projeto de pesquisa (tais como, passagem para o local da pesquisa, alimentação no local da pesquisa ou exames para realização da pesquisa) serão cobertas pelo pesquisador responsável.

Caso haja algum dano direto ou indireto decorrente de sua participação na pesquisa, você deverá buscar ser indenizado, obedecendo-se as disposições legais vigentes no Brasil. 
Os resultados da pesquisa serão divulgados na Universidade de Brasília, podendo ser publicados posteriormente, em reuniões, eventos científicos e/ou publicados em periódicos científicos. Os dados e materiais serão utilizados somente para esta pesquisa e ficarão sob a guarda do pesquisador por um período de cinco anos, após isso serão destruídos.

Se você tiver qualquer dúvida em relação à pesquisa, por favor, telefone para: Íris Caroline dos Santos, no telefone (61) 98375-8525/ 3702-7709 ou pelo e-mail: iriscarol@hotmail.com, ou Dra Maria Cristina Soares Rodrigues, na Universidade de Brasília, telefone (61) 98237-8710/3107-1711 ou pelo e-mail: mcsoares@unb.br, podendo telefonar a qualquer hora e realizar ligação a cobrar.

Este projeto foi aprovado pelo Comitê de Ética em Pesquisa da Faculdade de Ciências da Saúde (CEP/FS) da Universidade de Brasília. O CEP é composto por profissionais de diferentes áreas cuja função é defender os interesses dos participantes da pesquisa em sua integridade e dignidade e contribuir no desenvolvimento da pesquisa dentro de padrões éticos. As dúvidas com relação à assinatura do TCLE ou os direitos do participante da pesquisa podem ser esclarecidos pelo telefone (61) 3107-1947 ou do e-mail cepfs@ unb.br ou cepfsunb@gmail.com, horário de atendimento de 10:00hs às 12:00hs e de 13:30hs às 15:30hs, de segunda a sexta-feira. O CEP/FS se localiza na Faculdade de Ciências da Saúde, Campus Universitário Darcy Ribeiro, Universidade de Brasília, Asa Norte.

Caso concorde em participar, pedimos que assine este documento que foi elaborado em duas vias, uma ficará com o pesquisador responsável e a outra com você.

Brasília, de de

Nome / assinatura

Íris Caroline dos Santos Pesquisadora
Maria Cristina Soares Rodrigues Pesquisadora Responsável/Orientadora 
ANEXOS 


\section{ANEXO A - AUTORIZAÇÃO PARA UTILIZAÇÃO DO INSTRUMENTO (CARTA)}

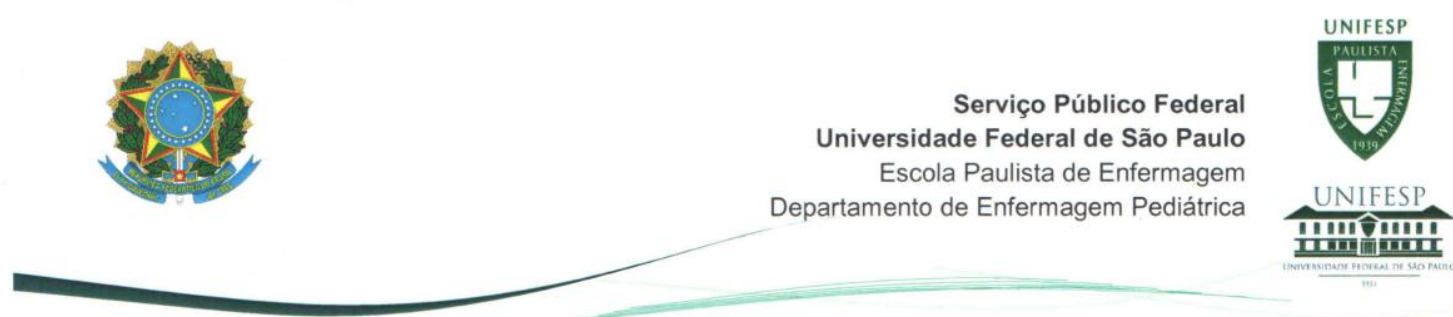

A/C Maria Cristina Soares Rodrigues

Universidade de Brasília, Distrito Federal, Brasil.

Prezada Professora

Agradecemos o seu interesse pelo estudo intitulado "Compreensão de alunos de cursos de graduação em enfermagem e medicina sobre segurança do paciente".

A respeito de sua solicitação para o uso do questionário de segurança do paciente segue abaixo o consentimento formal.

Questionário sobre a compreensão de alunos de cursos de graduação em enfermagem e medicina sobre segurança do paciente

Formulário de Autorização

Autor responsável

Maria Cristina Soares Rodrigues

Universidade de Brasília, Distrito Federal, Brasil.

A ser publicado/produzido por:

Maria Cristina Soares Rodrigues e Íris Caroline dos Santos

\section{Especificações}

1- Nenhuma alteração, adição ou deleção é permitida.

2- A permissão somente se aplica à pesquisa especificada nesta correspondência.

3- A fonte original deve ser citada: Yoshikawa JM, Sousa BEC, Peterlini MAS, Kusahara DM, Pedreira MLG, Avelar AFM. Comprehension of undergraduate students in nursing and medicine on patient safety. Acta paul. enferm. 2013; 26(1):21-9.

A permissão dos autores concedida nos termos acima mencionados é representada por:

Mavilde L. G. Pedreira. RN, PhD

Professor Associado

Escola Paulista de Enfermagem

Universidade Federal de São Paulo

Solicitante

Nome: Maria Cristina Soares Rodrigues

Endereço: Fundação Universidade de Brasília, Campus Universitário Darcy Ribeiro, Faculdade de Ciências da Saúde, Departamento de Enfermagem, Asa Norte, CEP: 70910-900, Brasília - DF.

Data: 05/05/2017

Assinatura: MeRoderijuenes

๑๐ 2013 Escola Paulista de Enfermagem / Universidade Federal de São Paulo

Rua Napoleão de Barros, 754 - $1^{\circ}$ Andar - Vila Clementino - CEP 04024-002 - São Paulo SP - Tel: +55 1150831965 
ANEXO B - AUTORIZAÇÃO PARA UTILIZAÇÃO DO INSTRUMENTO (E-MAIL)

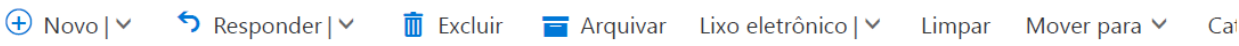

Re: A/C Profa. Dra. Mavilde - Carta de Autorização

ariane.machado@unifesp.br

qui 04/05/2017 17:24

Para: Mavilde (mpedreira@unifesp.br)

Cc: Íris Caroline (iriscarol@hotmail.com); Maria Cristina Soares Rodrigues (sr.mariacristina@gmail.com); maria cristina soares ro

TCC/pibic

Você respondeu em 05/05/2017 13:36.

Permissão uso do questi...

$2 \mathrm{MB}$

Baixar Salvar no OneDrive - Pessoal

Prezadas Íris e Profa. Maria Cristina, boa tarde!

encaminho o formulário para autorização de uso do questionário.

Solicito que preencham, assinem e encaminhem para este e-mail.

Muito obrigada!

Atenciosamente, Ariane Avelar

Citando Mavilde <mpedreira@unifesp.br>:

> Prezada Íris e prof.a Maria Cristina

$>$

$>$ É um prazer receber seu contato e interesse no uso do instrumento de pesquisa

$>$ Em breve retornaremos a carta de autorização

$>$

$>$ Att

$>$ Prof.a Mavilde Pedreira

$>$ Enviado do meu iPhone

$>>$ Em 2 de mai de 2017, às 16:55, Íris Caroline

$>>$ <iriscarol@hotmail.com> escreveu:

$>>$

$>>$ Prezada Profa. Dra. Mavilde,

$>>$

$>>$

>> Meu nome é Íris Caroline dos Santos, sou aluna de Graduação em

>> Enfermagem da Faculdade de Ciências da Saúde na Universidade de

> > Brasília - UnB, e estou sob a orientação da Profa. Dra. Maria

> > Cristina Soares Rodrigues para a elaboração do meu Trabalho de

> > Conclusão de Curso, que tem como objetivo averiguar o entendimento

> > dos alunos de enfermagem da nossa universidade sobre o erro humano

>> e a segurança do paciente. Temática esta, que foi abordada na

> > pesquisa "Compreensão de Alunos de Cursos de Graduação em

>> Enfermagem e Medicina sobre Segurança do Paciente" de YOSHIKAWA et

$>>$ al., 2013 .

>> Como autora correspondente deste estudo, entramos em contato para

> > solicitar a autorização para utilizar o questionário validado em

$>>$ nossa pesquisa.

$>>$

>> Segue em anexo a carta com pedido formal de autorização do instrumento

$>>$

> > Colocamo-nos a disposição para dúvidas, esclarecimentos e sugestões.

$>>$

$>>$

>> Desde já, agradecemos pela atenção e aguardamos retorno. 


\section{ANEXO C - AUTORIZAÇ̃̃o DA COORDENAÇÃO DO CURSO DE ENFERMAGEM PARA O DESENNVOLVIMENTO DA PESQUISA}

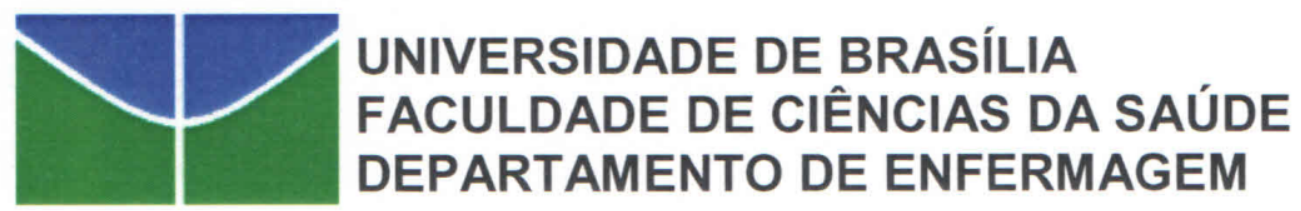

\section{AUTORIZAÇÃO PARA DESENVOLVIMENTO DE PESQUISA}

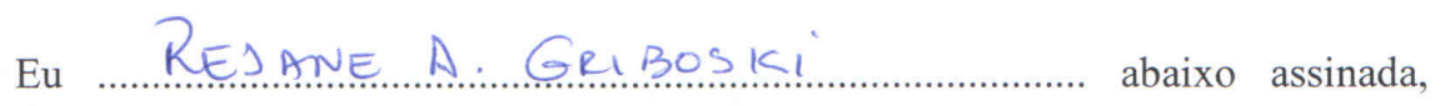
responsável pela coordenação do Curso de Graduação em Enfermagem, da Faculdade de Ciências da Saúde, da Universidade de Brasília, autorizo a realização do estudo “O entendimento do erro humano e a segurança do paciente na visão dos estudantes de enfermagem", a ser conduzido pela pesquisadora Íris Caroline dos Santos, aluna do Curso de Graduação em Enfermagem, sob a responsabilidade da professora orientadora Dra Maria Cristina Soares Rodrigues, para fins de elaboração do seu Trabalho de Conclusão de Curso.

Fui informada, pelo responsável do estudo, sobre as características e objetivos da pesquisa, bem como das atividades que serão realizadas junto aos estudantes do curso que coordeno.

Estou ciente das responsabilidades como instituição participante do presente projeta de pesquisa e do compromisso no resguardo da segurança e bem-estar dos participantes de pesquisa nela recrutados.

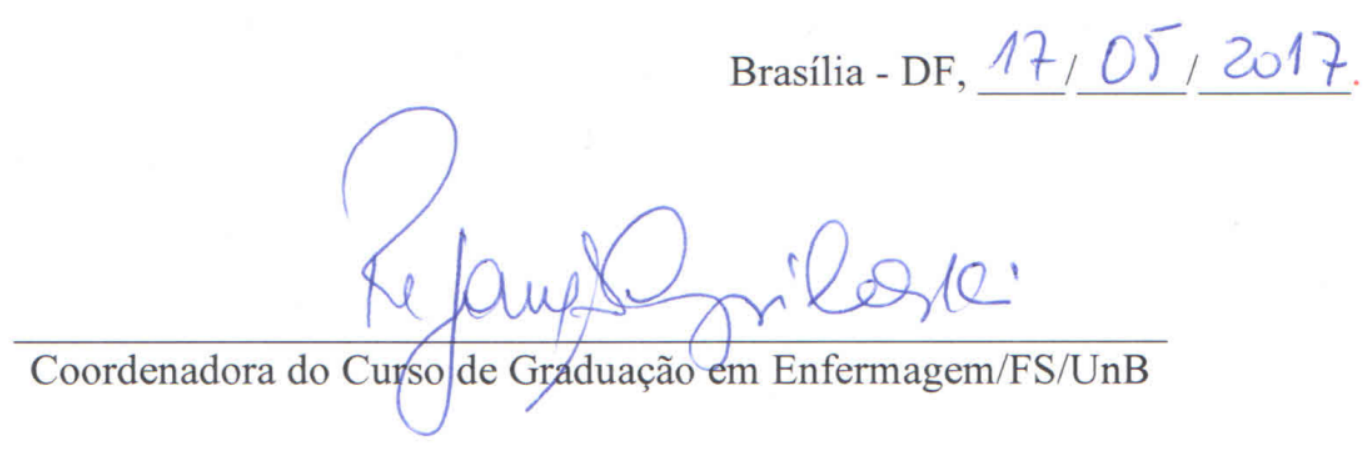




\section{ANEXO D - AUTORIZAÇÃO DA CHEFIA DO DEPARTAMENTO DE ENFERMAGEM PARA O DESENVOLVIMENTO DA PESQUISA}

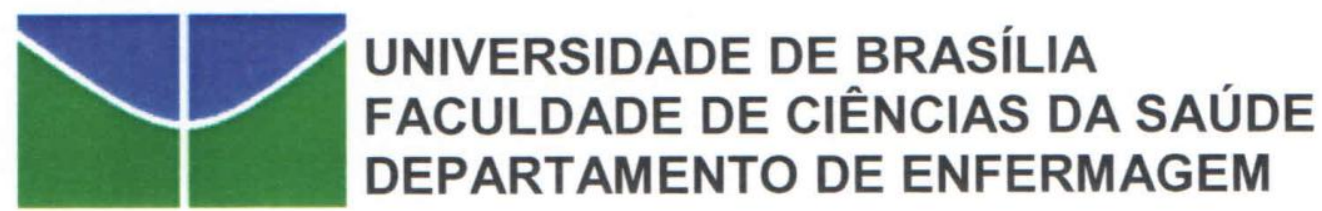

\section{AUTORIZAÇÃO PARA DESENVOLVIMENTO DE PESQUISA}

Eu DANIELLA SOARES DOS SANTOOS..., abaixo assinada, Chefe do Departamento de Enfermagem, da Faculdade de Ciências da Saúde, da Universidade de Brasília, autorizo a realização do estudo "O entendimento do erro humano e a segurança do paciente na visão dos estudantes de enfermagem", a ser desenvolvido pela pesquisadora Íris Caroline dos Santos, aluna do Curso de Graduação em Enfermagem, sob a responsabilidade da professora orientadora Dra Maria Cristina Soares Rodrigues, para fins de elaboração do seu Trabalho de Conclusão de Curso.

Fui informada, pelo responsável do estudo, sobre as características e objetivos da pesquisa, bem como das atividades que serão realizadas junto aos estudantes do Curso de Graduação vinculados ao Departamento de Enfermagem.

Estou ciente das responsabilidades como instituição participante do presente projeta de pesquisa e do compromisso no resguardo da segurança e bem-estar dos participantes de pesquisa nela recrutados.

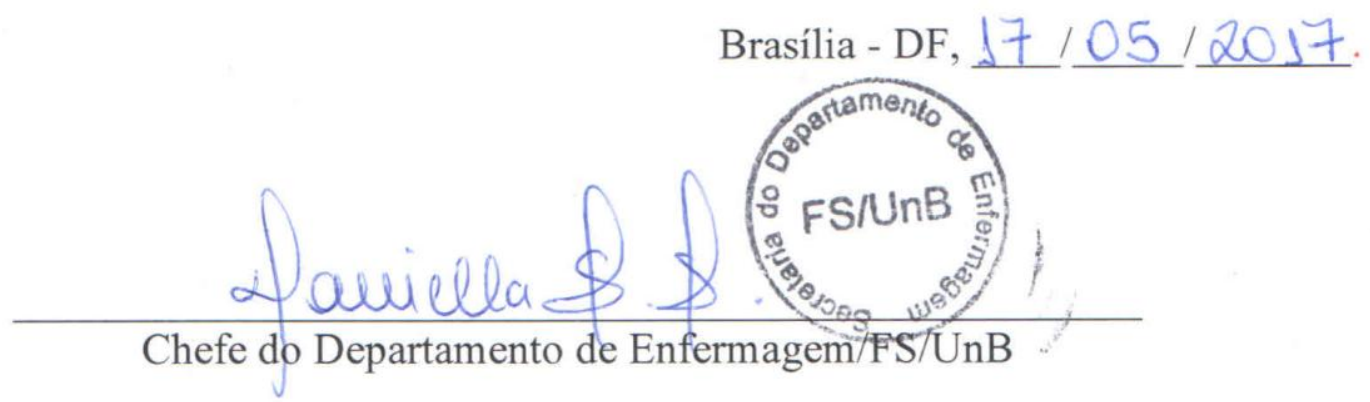




\section{ANEXO E - PARECER CONSUBSTANCIADO DO CEP}

\section{UNB - FACULDADE DE CIÊNCIAS DA SAÚDE DA UnB UNIVERSIDADE DE BRASÍLIA}

\section{PARECER CONSUBSTANCIADO DO CEP}

\section{DADOS DO PROJETO DE PESQUISA}

Título da Pesquisa: O ENTENDIMENTO DO ERRO HUMANO E A SEGURANÇA DO PACIENTE NA VISÄO DOS ESTUDANTES DE ENFERMAGEM

Pesquisador: Maria Cristina Soares Rodrigues

Área Temática:

Versão: 1

CAAE: 82254118.0 .0000 .0030

Instituição Proponente: Programa de Pós Graduação em Enfermagem - Mestrado - Universidade de

Patrocinador Principal: Financiamento Próprio

\section{DADOS DO PARECER}

Núm ero do Parecer. 2.526 .786

Apresentação do Projeto:

"A temática segurança do paciente na formaçẫo dos estudantes da área da saúde vem se mostrando cada vez mais relevante e impactante, com vistas à melhoria da atuação profissional, para a prestação de um cuidado mais qualificado e eficiente ao paciente, sem gerar possiveis danos. Nesse prisma, este estudo tem como objetivo verificar o entendimento de estudantes de enfermagem sobre o erro humano e a segurança do paciente. Trata-se de estudo descritivo, transversal, com abordagem quantitativa, vinculado a Trabalho de Conclusão de Curso. Será aplicado um questionário que avalia aspectos atitudinais e conceituais sobre a temática, a estudantes de graduaçẫo em enfermagem do $2^{\circ}$ ao $10^{\circ}$ semestre da Universidade de Brasília, campus Darcy Ribeiro, nos meses de março e abril de 2018. Espera-se contribuir com um diagnóstico situacional sobre o conhecimento dos estudantes a respeito do tema, a fim de indicar possíveis açốes para o aprimoramento do currículo vigente, que possibilite a formaçẫo de futuros profissionais mais preparados e capacitados para atuarem na perspectiva da segurança do paciente."

"Metodologia Proposta: "Trata-se de um estudo transversal, descritivo, com abordagem quantitativa. Para Pereira (2011), os estudos transversais verificam as medidas de exposição e efeito ao mesmo tempo, e os estudos de cunho descritivo têm o objetivo de informar sobre a distribuiçẵo de um evento na populaçắ, em termos quantitativos. Portanto, este estudo traduz um

\footnotetext{
Endereço: Faculdade de Ciências da Saúde - Campus Darcy Ribeiro

Bairro: Asa Norte

UF: DF Município: BRASILIA

CEP: $70.910-900$

Telefone $\quad(61) 3107-1947$

E-mail: cepfsunb@gmail.com
} 


\section{UNB - FACULDADE DE CIÊNCIAS DA SAÚDE DA UNIVERSIDADE DE BRASÍLIA}

Continuaçẫo do P arecer: 2.526 .786

\begin{tabular}{|c|c|c|c|c|}
\hline Outros & CV_Lattes_Iris_dos_Santos.pdf & $14: 52: 31$ & Soares Rodrigues & Aceito \\
\hline Outros & AUTORIZACAO_COORDENACAO.pdf & $\begin{array}{c}11 / 01 / 2018 \\
16: 41: 20\end{array}$ & $\begin{array}{l}\text { Maria Cristina Soares } \\
\text { Rodrigues }\end{array}$ & Aceito \\
\hline Outros & AUTORIZACAO_CHEFIA.pdf & $\begin{array}{c}11 / 01 / 2018 \\
16: 41: 00\end{array}$ & $\begin{array}{l}\text { Maria Cristina Soares } \\
\text { Rodrigues }\end{array}$ & Aceito \\
\hline Outros & AUTORIZACAO_COORDENACAO.doC & $\begin{array}{c}11 / 01 / 2018 \\
16: 40: 03\end{array}$ & $\begin{array}{l}\text { Maria Cristina Soares } \\
\text { Rodrigues }\end{array}$ & Aceito \\
\hline Outros & AUTORIZACAO_CHEFIA.doC & $\begin{array}{c}11 / 01 / 2018 \\
16: 39: 22\end{array}$ & $\begin{array}{l}\text { Maria Cristina Soares } \\
\text { Rodrigues }\end{array}$ & Aceito \\
\hline $\begin{array}{l}\text { Declaração de } \\
\text { Instituiçẫo e } \\
\text { Infraestrutura }\end{array}$ & TERMO_DE_CONCORDANCIA.doC & $\begin{array}{c}11 / 01 / 2018 \\
16: 36: 33\end{array}$ & $\begin{array}{l}\text { Maria Cristina Soares } \\
\text { Rodrigues }\end{array}$ & Aceito \\
\hline $\begin{array}{l}\text { Declaração de } \\
\text { Instituiçẫo e } \\
\text { Infraestrutura }\end{array}$ & TERMO_DE_CONCORDANCIA.pdf & $\begin{array}{c}11 / 01 / 2018 \\
16: 34: 52\end{array}$ & $\begin{array}{l}\text { Maria Cristina Soares } \\
\text { Rodrigues }\end{array}$ & Aceito \\
\hline $\begin{array}{l}\text { Declaração de } \\
\text { Pesquisadores }\end{array}$ & $\begin{array}{l}\text { TERMO_DE_RESPONSABILIDADE_E_ } \\
\text { COMPROMISSO.doc }\end{array}$ & $\begin{array}{c}11 / 01 / 2018 \\
16: 29: 39\end{array}$ & $\begin{array}{l}\text { Maria Cristina Soares } \\
\text { Rodriques }\end{array}$ & Aceito \\
\hline Orçamento & PLANILHA.doc & $\begin{array}{c}11 / 01 / 2018 \\
16: 26: 56\end{array}$ & $\begin{array}{l}\text { Maria Cristina Soares } \\
\text { Rodriques }\end{array}$ & Aceito \\
\hline Orçamento & PLANILHA.pdf & $\begin{array}{c}11 / 01 / 2018 \\
16: 26: 44\end{array}$ & $\begin{array}{l}\text { Maria Cristina Soares } \\
\text { Rodriques }\end{array}$ & Aceito \\
\hline $\begin{array}{l}\text { TCLE / Termos de } \\
\text { Assentimento / } \\
\text { Justificativa de } \\
\text { Ausência }\end{array}$ & TCLE.doc & $\begin{array}{c}11 / 01 / 2018 \\
16: 22: 12\end{array}$ & $\begin{array}{l}\text { Maria Cristina Soares } \\
\text { Rodrigues }\end{array}$ & Aceito \\
\hline Cronograma & CRONOGRAMA.pdf & $\begin{array}{c}11 / 01 / 2018 \\
16: 20: 53\end{array}$ & $\begin{array}{l}\text { Maria Cristina Soares } \\
\text { Rodrigues }\end{array}$ & Aceito \\
\hline Outros & Carta_encaminhamento_CEP.doc & $\begin{array}{c}11 / 01 / 2018 \\
16: 10: 34\end{array}$ & $\begin{array}{l}\text { Maria Cristina Soares } \\
\text { Rodrigues }\end{array}$ & Aceito \\
\hline Cronograma & CRONOGRAMA.doCX & $\begin{array}{c}11 / 01 / 2018 \\
15: 49: 06\end{array}$ & $\begin{array}{l}\text { Maria Cristina Soares } \\
\text { Rodrigues }\end{array}$ & Aceito \\
\hline Outros & $\begin{array}{l}\text { CV_Lattes_Maria_Cristina_Soares_Rodr } \\
\text { iques.pdf }\end{array}$ & $\begin{array}{c}11 / 01 / 2018 \\
15: 45: 19 \\
\end{array}$ & $\begin{array}{l}\text { Maria Cristina Soares } \\
\text { Rodriques }\end{array}$ & Aceito \\
\hline $\begin{array}{l}\text { TCLE / Termos de } \\
\text { Assentimento / } \\
\text { Justificativa de } \\
\text { Ausência }\end{array}$ & TCLE.pdf & $\begin{array}{c}11 / 01 / 2018 \\
14: 41: 30\end{array}$ & $\begin{array}{l}\text { Maria Cristina Soares } \\
\text { Rodrigues }\end{array}$ & Aceito \\
\hline $\begin{array}{l}\text { Declaraçã̃o de } \\
\text { Pesquisadores }\end{array}$ & $\begin{array}{l}\text { TERMO_DE_RESPONSABILIDADE_E_ } \\
\text { COMPROMISSO.pdf }\end{array}$ & $\begin{array}{c}11 / 01 / 2018 \\
14: 40: 45 \\
\end{array}$ & $\begin{array}{l}\text { Maria Cristina Soares } \\
\text { Rodrigues }\end{array}$ & Aceito \\
\hline Outros & $\begin{array}{l}\text { CARTA_DE_ENCAMINHAMENTO_CEP } \\
\text { pdf }\end{array}$ & $\begin{array}{c}11 / 01 / 2018 \\
14: 39: 08 \\
\end{array}$ & $\begin{array}{l}\text { Maria Cristina Soares } \\
\text { Rodrigues }\end{array}$ & Aceito \\
\hline
\end{tabular}

Situação do P arecer:

Aprovado

\section{Neces sita A preciação da CONEP:}

Endereço: Faculdade de Ciências da Saúde - Campus Darcy Ribeiro

Bairro: Asa Norte

UF: DF

Telefone

(61) $3107-1947$
CEP: $70.910-900$

E-mail: cepfsunb@gmail.com 


UNB - FACULDADE DE
CIÊNCIAS DA SAÚDE DA
UnB PlVERSIDADE DE BRASÍLIA

Contiruaçẫo do P arecer: 2.526 .786

Nầo

BRASILIA, 05 de Março de 2018

Assinado por:

Marie Togashi

(Coordenador)

Endereço: Faculdade de Ciências da Saúde - Campus Darcy Ribeiro

Bairro: Asa Norte CEP: 70.910-900

UF: DF Município: BRASILIA

Telefone (61)3107-1947 E-mail: cepfsunb@gmail.com 